\title{
Optimization of insulation in ventilated hinged facade systems
}

\author{
Irina Maltseva ${ }^{1, *}$, Aleksandr Elokhov $^{2}$, Vitaliy Borisov ${ }^{3}$, and Alexey Verkhovskiy ${ }^{4}$ \\ ${ }^{1}$ URFU, Department of Civil Engineering and Architecture, 620002 Yekaterinburg, Russia \\ ${ }^{2}$ Institute of Passive House, Production Department, 117405 Moscow, Russia \\ ${ }^{3}$ LLC "PAROC", 127473 Moscow, Russia \\ ${ }^{4}$ Research Institute of Building Physics of the Russian Academy Architecture and Construction \\ Science, 127238 Moscow, Russia
}

\begin{abstract}
The system of hinged ventilated facades is available for a long time and is now widely used in the construction of new and reconstruction of existing buildings for various purposes. As practice shows, the problems associated with the operation of these facade systems are usually caused by mistakes in the design, selection of components and installation of the system. Ventilated facade is a multi-layered enclosing structure, which includes a layer of insulation. Mineral wool slabs are ideal for this facade system, as it has low thermal conductivity, resistance to temperature changes and excellent vapor permeability, which allows to fully open the potential of a ventilated air layer. In the article two ways of installation of thermal insulation are considered: single-layer and two-layer with different types of air interlayer: closed, weakly and strongly ventilated. In accordance with the requirements of Russian and European regulatory documents, the effect of gaps between the thermal insulation plates in a single-layer and two-layer design on the reduction of the heat transfer resistance of hinged facade systems with an air gap was estimated by calculating 2-dimensional temperature fields. The coefficient of thermotechnic uniformity was also defined. As a result, optimal variants of thermal insulation and types of bases for fixing thermal insulation are suggested.
\end{abstract}

\section{Introduction}

The system of hinged ventilated facades is available for a long time and is now widely used in the construction of new and reconstruction of existing buildings for various purposes. The system of hinged ventilated facades is known for a long time and is now widely used in the construction of new and reconstruction of existing buildings with different areas of destination. Successful implement and development of these systems in Russia was based on the high performance characteristics inherent in this type of building structures, as well as the improvment of the energy efficiency of buildings and the increased requirements for comfort and quality of life [1]. According to the results of 2017, total number of tenders for

\footnotetext{
*Corresponding author: 3724316@mail.ru
} 
ventilated facades was $16 \%$ of the total sum of applications for construction and capital repairs, and the area of the facades insulated with the help of systems of ventilated hinged facades was about 20 million square meters.

Ventilated facade is a multi-layered enclosing structure, inside of which an air gap is provided between the thermal insulation and the outer decorative-protective layer. The air that circulates freely inside the gap facilitates the ventilation of the internal layers of the system and the moisture outflow accumulated during operation, thereby ensuring an optimum moisture balance within the structure, which significantly increases the service life of the building structures and preserves their thermal and technical characteristics [2].

\section{Features of installation of thermal insulation}

Mineral wool plates are used as a heat-insulating layer in systems of hinged ventilated facades, as they are ideal for this system. Mineral wool insulation has low thermal conductivity, resistance to temperature changes and high vapor permeability, which allows to fully open the potential of a ventilated air gap. Also characteristic features of mineral wool are its incombustibility and ability to fit tightly to the insulated surface and the elements of the subsystem, which is an obligatory requirement for thermal insulation in this class of facade structures.

As practice shows, the problems associated with the operation of ventilated facade systems can be caused both by errors in the design and selection of components and the installation of the system [3]. The quality of installation of a hinged ventilated facade system affects the heat loss of the shell of the building as a whole. The most significant problem in the installation of elements of a ventilated facade is the installation of thermal insulation. Improperly installed insulation can reduce the effect of installing the ventilated facade to zero, because, first of all, this solution is a thermal insulation system that protects the load-bearing structures from the negative impact of the environment, and only then is considered as a way of performing design and architectural tasks. Thermal insulation boards should be installed close to each other. Only then the maximum effect from the heatinsulating layer is achieved. All gaps between the plates will be thermal bridges that lower the thermal resistance of the entire enclosing structure, since cold air constantly circulating in the air layer contributes to the emission of heat through the joints of the thermal insulation boards [4]. Taking into the account the fact that the total length of such joints on the facade is quite significant, it will have a huge negative impact on the efficiency of insulation.

Unfortunately, to the quality of the insulation installation is not always given due attention, and as a result, installation takes place with significant disruptions (fig. 1). The allowed value of the unfilled seam is $2 \mathrm{~mm}$ [5]. In reality, it is simply impossible to achieve the required width of the gap between the plates, since sometimes uneven surfaces needed to be insulated and it is impossible to achieve the required quality of joints. In hinged facade systems, a single-layer or two-layer thermal insulation scheme can be used. In this connection, it is recommended to use a two-layer scheme of insulation installation in Russia, when the slabs of the outer layer overlap the joints of the internal, thus avoiding the formation of thermal bridges caused by gaps between the insulation plates [6]. Unfortunately, trying to save money, some customers choose a single-layer thermal insulation scheme, since it is considered that it is somewhat cheaper in comparison with a two-layer scheme, in view of the smaller number of works. But how much is this saving justified? 

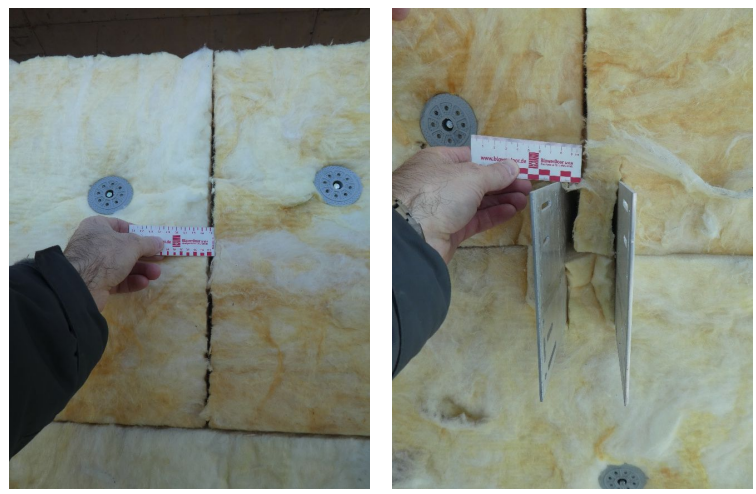

Fig. 1. Examples of poor-quality installation of thermal insulation in hinged ventilated facades (the gaps between heat-insulating slabs range from 5 to $15 \mathrm{~mm}$ ).

\section{Model and calculation procedure}

The authors of the article carried out the research of the effect of various insulation schemes (single-layer and two-layer) and gaps between thermal insulation plates on the values of the reduced resistance to heat transfer and the heat transfer performance uniformity factor of hinged facade systems with an air gap using the method of twodimensional temperature fields. The calculations were carried out in accordance with the requirements of European standards [7].

As the base of facade systems were chosen: monolithic reinforced concrete $160 \mathrm{~mm}$ thick or masonry from aerated concrete blocks D500 $300 \mathrm{~mm}$ thick with cement-sand plaster $20 \mathrm{~mm}$ thick on the inner side. For single-layer thermal insulation mineral wool 120 $\mathrm{mm}$ thick was used. While a two-layer insulation examined two variants: top - Paroc WAS35 $30 \mathrm{~mm}$, bottom Paroc WAS120 $90 \mathrm{~mm}$ or top - Paroc WAS35 $50 \mathrm{~mm}$, bottom Paroc WAS120 $70 \mathrm{~mm}$. The heat transfer coefficient of the materials are given in Table 1 . The design temperatures of the outdoor and indoor air are taken: $t_{\text {ext }}=-25^{\circ} \mathrm{C}$ и $t_{\text {int }}=+20^{\circ} \mathrm{C}$. Resistance to heat dissipation of the outer surface of walls $R_{s e}$ and resistance to heat transfer of the internal surface of walls, ceiling $R_{s i}$ was taken equal to 0,13 [7].

Table 1. Heat transfer coefficient of used materials.

\begin{tabular}{|c|c|}
\hline Name & $\boldsymbol{\lambda}[\mathbf{W} /(\mathbf{m} . \mathbf{K})]$ \\
\hline Cement-sand plaster & 0.930 \\
\hline Aerated concrete & 0.132 \\
\hline Monolithic reinforced concrete & 2.040 \\
\hline Paroc WAS35 & 0.038 \\
\hline Paroc WAS120 & 0.041 \\
\hline Mineral wool & 0.040 \\
\hline
\end{tabular}

In calculations, according to DIN EN ISO 6946, the heat dissipation of the external and internal surfaces is taken depending on the type of ventilated layer between the wall structure and the facade. This standard considers three types of these gaps (Table 2). 
Table 2. Air gaps.

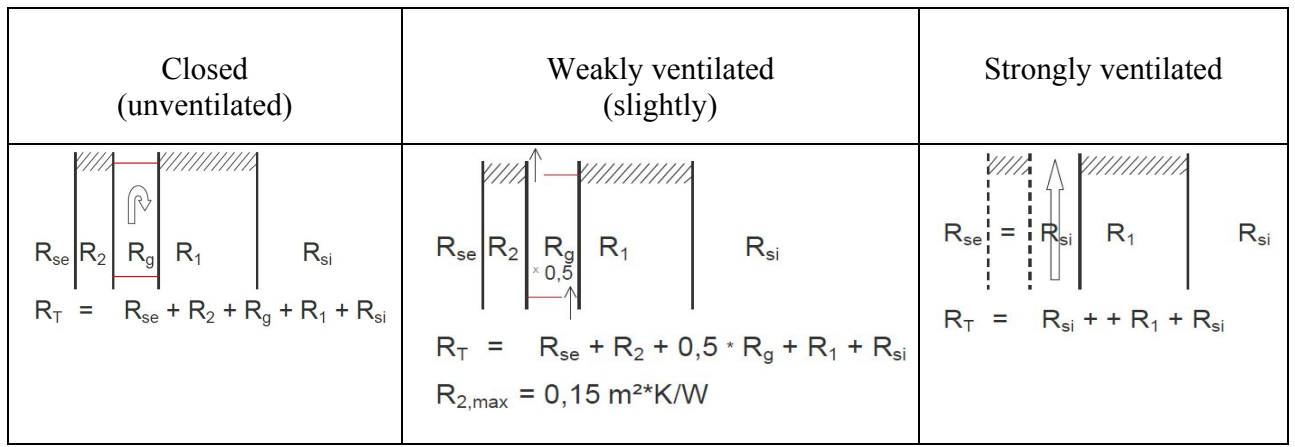

An air gap is considered to be a closed if the area of the openings communicating with the outside air is less than $500 \mathrm{~mm}^{2}$ per 1 running meter in length (in the horizontal direction) of the vertical structure (for vertical air layers). An air gap is considered to be weakly ventilated if the area of the openings communicating with the outside air is in the range $500-1500 \mathrm{~mm}^{2}$ per 1 running meter in length (in the horizontal direction) of a vertical structure (for vertical air gaps) or per $1 \mathrm{~m}^{2}$ of a horizontal structure (for horizontal air gaps). An air gap is considered to be a strongly ventilated interlayer if the area of openings communicating with the outside air is over $1500 \mathrm{~mm}^{2}$ per 1 running meter of the length of the vertical structure or per $1 \mathrm{~m}^{2}$ of the area of the horizontal structure.

Table 3. Results of calculations in accordance with DIN EN ISO 6946.

\begin{tabular}{|c|c|c|c|}
\hline & \multicolumn{2}{|c|}{$\begin{array}{c}\text { Resistance to heat transfer: } \mathrm{R}_{0}{ }^{\text {con }} / \mathrm{R}_{0}{ }^{\mathrm{r}},\left(\mathrm{m}^{2} . \mathrm{K}\right) / \mathrm{W} \\
\text { (heat transfer performance uniformity factor } \mathrm{r})\end{array}$} \\
\hline Insulation & $\begin{array}{c}\text { One layer } \\
\text { mineral wool } \\
120 \mathrm{~mm}\end{array}$ & $\begin{array}{c}\text { Top Paroc WAS35 } \\
30 \text { mm, bot Paroc } \\
\text { WAS120 } 90 \mathrm{~mm}\end{array}$ & $\begin{array}{c}\text { Top Paroc WAS35 } \\
50 \mathrm{~mm} \text {, bot Paroc } \\
\text { WAS120 70 mm }\end{array}$ \\
\hline \multicolumn{4}{|c|}{ Option 1. A gap in thermal insulation $2 \mathrm{~mm}$ wide } \\
\hline $\begin{array}{c}\text { Monolithic reinforced concrete } \\
160 \text { mm thick }\end{array}$ & $\begin{array}{c}3.338 / 1.599 \\
(\mathrm{r}=0.479)\end{array}$ & $\begin{array}{c}3.323 / 3.135 \\
(\mathrm{r}=0.943)\end{array}$ & $\begin{array}{c}3.362 / 3.049 \\
(\mathrm{r}=0.907)\end{array}$ \\
\hline $\begin{array}{c}\text { Masonry from aerated concrete } \\
\text { blocks D500 300 mm thick }+ \\
\text { cement-sand plaster 20 mm }\end{array}$ & $\begin{array}{c}5.554 / 3.524 \\
(\mathrm{r}=0.634)\end{array}$ & $\begin{array}{c}5.539 / 5.348 \\
(\mathrm{r}=0.965)\end{array}$ & $\begin{array}{c}5.557 / 5.250 \\
(\mathrm{r}=0.941)\end{array}$ \\
\hline \multicolumn{4}{|c|}{ Option 2. A gap in thermal insulation 4 mm wide } \\
\hline $\begin{array}{c}\text { Monolithic reinforced concrete } \\
160 \text { mm thick }\end{array}$ & $\begin{array}{c}3.338 / 1.530 \\
(\mathrm{r}=0.458)\end{array}$ & $\begin{array}{c}3.323 / 3.069 \\
(\mathrm{r}=0.923)\end{array}$ & $\begin{array}{c}3.362 / 3.004 \\
(\mathrm{r}=0.893)\end{array}$ \\
\hline $\begin{array}{c}\text { Masonry from aerated concrete } \\
\text { blocks D500 300 mm thick + } \\
\text { cement-sand plaster 20 mm }\end{array}$ & $\begin{array}{c}5.554 / 3.428 \\
(\mathrm{r}=0.617)\end{array}$ & $\begin{array}{c}5.539 / 5.287 \\
(\mathrm{r}=0.954)\end{array}$ & $\begin{array}{c}5.557 / 5.207 \\
(\mathrm{r}=0.934)\end{array}$ \\
\hline \multicolumn{4}{|c|}{ Option 3. A gap in thermal insulation 8 mm wide } \\
\hline $\begin{array}{c}\text { Monolithic reinforced concrete } \\
160 \text { mm thick }\end{array}$ & $\begin{array}{c}3.338 / 1.409 \\
(\mathrm{r}=0.422)\end{array}$ & $\begin{array}{c}3.323 / 2.957 \\
(\mathrm{r}=0.890)\end{array}$ & $\begin{array}{c}3.362 / 2.917 \\
(\mathrm{r}=0.868)\end{array}$ \\
\hline $\begin{array}{c}\text { Masonry from aerated concrete } \\
\text { blocks D500 300 mm thick + } \\
\text { cement-sand plaster 20 mm }\end{array}$ & $\begin{array}{c}5.554 / 3.258 \\
(\mathrm{r}=0.587)\end{array}$ & $\begin{array}{c}5.539 / 5.183 \\
(\mathrm{r}=0.936)\end{array}$ & $\begin{array}{c}5.557 / 5.133 \\
(\mathrm{r}=0.920)\end{array}$ \\
\hline
\end{tabular}

At the size of the plates of the warming layer $1000 \times 600 \mathrm{~mm}$, the area of the calculated fragment is $0.6 \mathrm{~m}^{2}$, in this case the gap length in the calculation fragment is $1.6 \mathrm{~m}$. With an 
increase in the area of the calculated fragment to $1 \mathrm{~m}^{2}$, we obtain a gap with length of 2.67 $\mathrm{m}$. Thus, the area of the openings communicating with the outside air is $S=2670 \cdot 2=5340 \mathrm{~mm}^{2}$. For the experiment, a facade system with a strongly ventilated air layer is taken, therefore, according to DIN EN ISO 6946: $R_{s e}=R_{s i}=0.13\left(\mathrm{~m}^{2} . \mathrm{K}\right) / \mathrm{W}$. For all types of insulation, the width of the gaps between thermal insulation boards with the following thicknesses are considered: 2,4 and $8 \mathrm{~mm}$, where $2 \mathrm{~mm}$ is the maximum permissible gap between the plates [5], and the values 4 and $8 \mathrm{~mm}$ are taken to evaluate the influence of increased gap on resistance to heat transfer.

\section{Results and discussion}

The calculations showed that for single-layer insulation, even the minimum allowed clearance of $2 \mathrm{~mm}$ leads to a significant reduction in the reduced resistance to heat transfer value, while the two-layer thermal insulation scheme remains effective (Table 3).

Similar calculations were carried out according to Russian standards [8-11]. The results of the simulation, produced by the Russian and European methods, are identical, which increases the level of confidence in the results obtained.

Table 4. Illustrations of calculations.

\begin{tabular}{|c|c|c|c|c|c|}
\hline Scheme & Material & $\begin{array}{c}\lambda, \\
\mathrm{W} / \mathrm{m} . \mathrm{K}\end{array}$ & Model & $t,{ }^{\circ} \mathrm{C}$ & $\begin{array}{l}\text { Temperature } \\
\text { fields }\end{array}$ \\
\hline 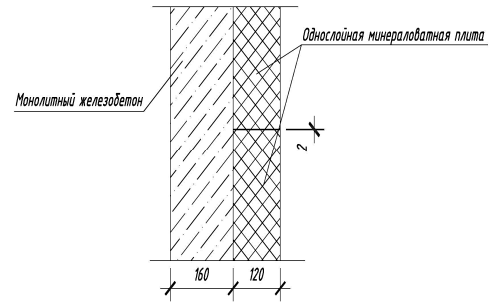 & $\begin{array}{l}\text { Reinf. } \\
\text { Concrete } \\
\\
\text { Mineral } \\
\text { Wool }\end{array}$ & 2.04 & & & \\
\hline 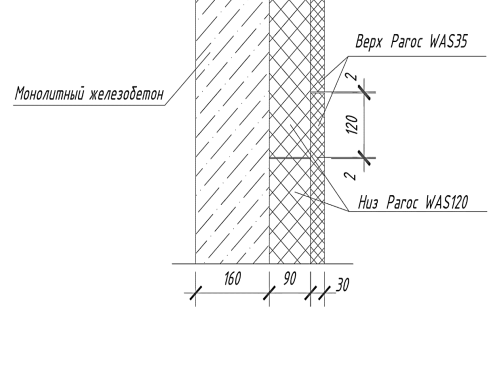 & $\begin{array}{l}\begin{array}{l}\text { Reinf. } \\
\text { Con- } \\
\text { crete }\end{array} \\
\text { Paroc } \\
\text { WAS35 } \\
\\
\\
\text { Paroc } \\
\text { WAS120 }\end{array}$ & $\begin{array}{l}2.04 \\
0.041\end{array}$ & & 量 & \\
\hline
\end{tabular}

According to the received data, the most effective option of insulation is a two-layer solution Top Paroc WAS35 $30 \mathrm{~mm}$, bottom Paroc WAS120 $90 \mathrm{~mm}$. This is explained by the fact that the gaps formed by the edges of the insulation plates of the lower layer of 90 
$\mathrm{mm}$ thick are covered by the upper $30 \mathrm{~mm}$ wind-shield layer and become a closed air intercalation with low thermal conductivity (the thermal conductivity of the air gap depends on the width of the gap). In this case, the bottom layer has the maximum thickness and the minimum effect from outside air in the insulation gaps.

Based on the results of calculations in accordance with DIN EN ISO 6946, we present several illustrations of calculations (Table 4). All calculations of two-dimensional temperature fields were made in the HEAT2 software package.

\section{Conclusions}

The calculations made allow us to make an unambiguous conclusion that a single-layer thermal insulation in hinged facade systems with a ventilated air layer is not effective. Even with a minimum allowable width of the seam of $2 \mathrm{~mm}$, the reduction in the reduced resistance to the heat transfer value of the facade fragment on the base of reinforced concrete can reach 52-55\%. To achieve maximum effect from the insulation there should not be any gaps. In reality, with a single-layer thermal insulation scheme, this can only be achieved by one method - sealing joints with a homogeneous material, which ultimately leads to higher costs for insulation work and, as a consequence, the inexpediency of applying such a thermal insulation scheme.

At the same time, the two-layer thermal insulation system maintains its efficiency even in conditions of installing thermal insulation with gaps exceeding the width allowed by the standards. That makes it optimal for use in the conditions of Russian reality.

\section{References}

1. E. Matseiko. Ventilated facades: "for" or "against"? Construction.ru/Russian online journal (2014)

2. Ya. Fedyakov. A brief analysis of the pros and cons of "wet" and hinged ventilated facades. Facades Russia/online journal facade market. Available on http://fasadrus.ru/kratkii-analiz-plyusov-i-minusov-article 376.html (2018)

3. Features of ventilated facades and their installation. GRAND :Facade systems. Available on http://fsgrand.ru/2016/02/15/ (2016)

4. I. Maltseva, A. Elokhov, K.Tkachuk, K. Maltceva, EDP Sciences, 146, 03002 (2018)

5. STO NOSTROY 2.14.67-2012. Cladding facade system with air gap. Installation works. General requirements to the production and control of works (2013)

6. A.A. Verkhovskiy, N.P. Umnyakova. Features of the application of external enclosing structures in cold climatic conditions Budownictwo o Zoptymalizowanym Potensjale Energetycznym, 2 (20), 129-134 (2017)

7. DIN EN ISO 6946:2007 Building components and building elements - Thermal resistance and thermal transmittance - Calculation method; German version EN ISO 6946:2007 (2007)

8. SP 50.13330.2012. Set of rules. Thermal performance of the buildings (2012)

9. SP 230.1325800.2015 Set of rules. Construction enclosing of buildings characteristics of thermal conductive of inclusions (2015)

10. GOST R 57356-2016/EN ISO 6946:2007, Building components and building elements - Thermal resistance and thermal transmittance - Calculation method, IDT (2017)

11. SP 50.13330.2012. Set of rules. Building climatology (2012) 